\title{
Ultrasound-assisted Rare Case of Misplaced Hemodialysis Catheter
}

\author{
Shalendra Singh ${ }^{1}$, Deepak Dwivedi ${ }^{2}$, Priya Taank ${ }^{3}$ \\ Journal of Medical Academics (2019): 10.5005/jp-journals-10070-0039
}

Sir,

Large-bore double-lumen hemodialysis catheterization using modified Seldinger technique through the right internal jugular vein (RIJV) is a common practice used for long-term hemodialysis in patients with end-stage kidney disease (ESKD). Hemodialysis catheter placement using ultrasound (USG) has significantly reduced the complications associated with blind puncture. ${ }^{1}$ Hemodialysis catheter insertion is associated with risk of inadvertent puncture of artery, pleura, and other nearby structures. The most common complication reported is malposition of the catheter, but this rarely causes any problems if it is identified and corrected at an early stage. However, as opposed to central venous catheterization (CVC), complications associated with hemodialysis catheterization are often serious owing to the large size of these catheters and due to the increased risk of bleeding at the time of dialysis. ${ }^{2}$ Even though USG can guide proper puncture of vessel desired, it cannot help in following or directing the course of the catheter after venipuncture. A post-catheterization chest X-ray is a must to correct this malposition, and the importance of a chest radiograph after placement of a catheter is highlighted by this case report. We report a case of an optimally placed USG-assisted RIJV hemodialysis catheter placement which was displaced to the right subclavian vein post insertion.

A 58-year-old male, a known case of ESKD, presented to the dialysis center for his routine hemodialysis. The patient had undergone creation of arteriovenous fistula recently and was dependent on temporary non-cuffed double-lumen catheter for vascular access. The patient had undergone multiple cannulations of the RIJV and subclavian vein in the past, and a history of infection of the catheter placed in the right subclavian vein had also been documented. Nevertheless, the patient was planned for a doublelumen right jugular vein hemodialysis catheter insertion in the intensive care unit for the dialysis. With aseptic precautions, under real-time USG, a 12-F double-lumen hemodialysis catheter was inserted using the modified Seldinger technique. Prior to dilatation of the tract, the guide wire placement inside RIJV was confirmed with USG by the appearance of a bright dot inside the RIJV. Slight difficulty was encountered in passing the guide wire at $10 \mathrm{~cm}$, but it was further advanced by gentle manipulation. No arrhythmias were noticed on insertion of the guide wire, but USG showed the guide wire tip inside the lumen of internal jugular vein. The tract was dilated, and the dialysis catheter was introduced uneventfully. However, when a postprocedure chest X-ray was taken to confirm the position of the catheter, it was found that the catheter tip had migrated into the right subclavian vein (Fig. 1).

A misplaced CVC refers to a catheter whose tip does not lie in the "ideal" position. The catheter misplacement may occur either due to faulty procedure/positioning during insertion or due to

\author{
1,2 Department of Anaesthesiology and Critical Care, Armed Forces \\ Medical College, Pune, Maharashtra, India \\ ${ }^{3}$ Department of Ophthalmology, Southern Command Hospital, Pune, \\ Maharashtra, India
}

Corresponding Author: Shalendra Singh, Department of Anaesthesiology and Critical Care, Armed Forces Medical College, Pune, Maharashtra, India, Phone: +91 9466332207, e-mail: drsinghafmc@ gmail.com

How to cite this article: Singh S, Dwivedi D, Taank P. Ultrasoundassisted Rare Case of Misplaced Hemodialysis Catheter. J Med Acad 2019;2(2):67-68.

Source of support: Nil

Conflict of interest: None

congenital or acquired anatomical anomalies. ${ }^{3}$ The index patient had multiple cannulations of the right jugular and subclavian vein in the past, as well as a history of infection of the catheter placed in the right subclavian vein. The misplacement in the present case reported may be due to misplacement of the guide wire into the right subclavian vein due to stenosis of the superior vena cava. Even though entry of the catheter into a planned vein can be ensured using USG transducer stabilization device, its subsequent passage cannot be controlled. ${ }^{4}$ To conclude, real-time USG increases the success rate of CVC placements, but postprocedure radiography is of paramount importance to confirm ideal catheter positioning prior to staring hemodialysis,

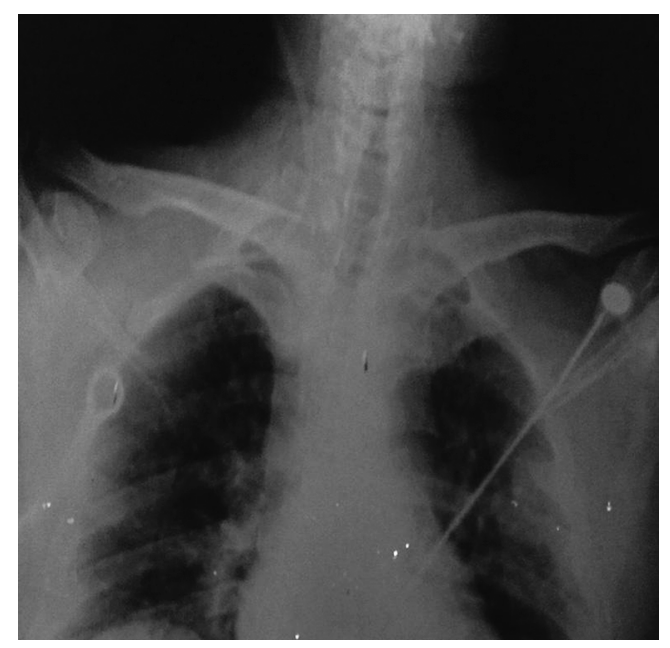

Fig. 1: Chest X-ray showing hemodialysis catheter in right subclavian vein

(c) The Author(s). 2019 Open Access This article is distributed under the terms of the Creative Commons Attribution 4.0 International License (https://creativecommons. org/licenses/by-nc/4.0/), which permits unrestricted use, distribution, and non-commercial reproduction in any medium, provided you give appropriate credit to the original author(s) and the source, provide a link to the Creative Commons license, and indicate if changes were made. The Creative Commons Public Domain Dedication waiver (http://creativecommons.org/publicdomain/zero/1.0/) applies to the data made available in this article, unless otherwise stated. 
especially in patients with past history of multiple accesses in the same vein.

\section{References}

1. Rabindranath KS, Kumar E, Shail R, et al. Ultrasound use for the placement of haemodialysis catheters. Cochrane Database Syst Rev 2011;11(11):CD005279. DOI: 10.1002/14651858.CD005279.pub4.
2. Bream PR Jr. Update on insertion and complications of central venous catheters for hemodialysis. Semin Intervent Radiol 2016;33(1):31-38. DOI: $10.1055 / \mathrm{s}-0036-1572547$.

3. Gibson F, Bodenham A. Misplaced central venous catheters: applied anatomy and practical management. Br J Anaesthe 2013;110(3): 333-346. DOI: 10.1093/bja/aes497.

4. Kaushal A, Bindra A, Singh S. Mobile phone holder as an ultrasound transducer stabilisation device: a novel technique. Indian J Anaesth 2018;62(8):635-636. DOI: 10.4103/ija.IJA_375_18. 